\title{
Chapter 7 \\ Searching for the Prehistoric Seafaring Craft Between Southeast Coast of China and the Pacific Islands
}

The historical documents and archaeological discoveries inform that a sophisticated maritime culture had been developed thousands of years ago along southeast coast of China and adjacent Southeast Asia. The indigenous Bai Yue (百越) ethnicities carried out early navigation between the coastal region East and Southeast Asia since Neolithic age, that is earlier before than the migration of Han people from North to South 2000 years ago (Chang, K.C. 1989; Rolett, B.V. 2007; Wu, C.M. 2019). These Neolithic seafaring groups have also been taken as the origin of the Pacific Austronesians (Chang, K.C. et al. 1964; Chang, K.C. 1987a; Rolett, B.V. et al. 2002; Wu, C.M. 2012a). By what kind of craft did they take on the great sea thousands of years ago? Archaeologists, historians, ethno-historians, and maritime culture researchers argued with different viewpoints.

Due to the close cultural relationship between the prehistoric indigenous people of southern China, Southeast Asia, and the Pacific Austronesians, the capability and seaworthy of the composite canoes of both outrigger and double-hulled canoe of the Austronesians enlightens us in the searching for the seafaring tool of the ancient Bai Yue. Recently, we researched a number of ethnographical and archaeological heritages of composite canoes discovered in southeast of China, such as the double-hulled "Fang Zhou" (舫舟) in ancient China, "Mother-Son Boat" (子母船) outrigger of Miao minority, and "Mangka" (蟒甲) outrigger in Taiwan aboriginal society, presenting a new clue for understanding the prehistoric seafaring craft between southeast coast of China and the Pacific Islands (Wu, C.M. 2008a, 2012b). 


\subsection{The Exploration for Seafaring Tools of the Ancestor of Bai Yue}

In the humanistic vision of Huaxia in Central Plains, the Island Yi (岛夷) and Bai Yue in the peripheries of "Southeastern Direction" were famous for maritime culture and "being good at using boats". The section of "Tribute of the $Y u$ Period" (禹贡) of the Book of Early History (Shangshu 尚书) records that "The Yangzhou region is located near the Huaihai (淮海) ocean", "the barbarians on the islands wear straw clothes, make and wear the bark... live along the rivers and seas", depicting the coastal and maritime landscape of Island Yi and Bai Yue ancestors (Ruan, Y. 2009: 312-313). The chapter of "Master Strategy Research (主术训)" of the Book of the Prince of Huainan (Huai'nanzi 淮南子) records that “despite being a great lord, the wise emperor Tang (汤) of Shang Dynasty was incapable of sailing on rivers and lakes as indigenous Yue people easily did" (Liu, A. et al. 2010: 126). The chapter of the "Biography of the Yue Territory" of the History of the Lost Yue Ethnicity (Yuejueshu 越绝书) records that “The character of the aboriginal Yue is crude and rush. They live in mountainous coast and travel by water, taking boats with oar as their main transportation tool. They skillfully sail the boat as fast as the howling wind" (Yuan, Kang 1985: 57-58). The theories of "Maritime Region of Southeastern Asia" (Lin, H. X. 1937) and "Asian Mediterranean" (Ling, C.S. 1954a) respectively proposed by Professor Lin Huixiang and Ling Chunsheng identified the maritime cultural tradition of the indigenous peoples along the southeast coast of China before the unification of Central Nation and the Han people migration to the south.

Archaeological investigations have shown that the ancestors of the indigenous Bai Yue were very active in Neolithic seafaring ranging from the coastal shipping to the oceanic voyage, showing in a large number of prehistoric maritime settlement patterns along the coast of mainland Eastern Asia since at least 7000 years ago. Such as, on the east coast, the Neolithic Hemudu (河姆渡) and Liangzhu (良渚) cultures dating from 7000 to 4000 years ago extended across the strait to the Zhoushan (舟山) archipelago, illustrating the successful development of Neolithic seascapes and the extension of oceanic exploration and maritime traffic of the prehistoric ancestors of $Y u$ Yue (于越) ( $\mathrm{Wu}, \mathrm{Y} . \mathrm{X}$. 1983). In the west coast of Taiwan Strait centering around the lower reaches of Minjiang (闽江) River Basin, hundreds of densely packed Neolithic shell midden sites were discovered along the coast and on nearshore islands such as Mazhu (马祖), Pingtan (平潭), Jinmen (金门), Dongshan (东山), and etc. sharing the same Neolithic cultural series of Keqiutou (壳丘头) 一 Tanshishan (是石山) - Huangguashan (黄瓜山) Huangtulun (黄土仑) cultures, reflecting the rising and subsequent prosperity of the Min Yue (闽越) maritime culture from 8000 to 3000BP (Lin, C.C. 1973; Xu, Q.H. 1988; FJPM 1991; FZMCRAT et al. 1995; Wu, C.M. 1995, 1996a; Wu, C.M. et al. 1998: 143-153; Chen, C.Y. 1999, 2012; Chen, C.Y. et al. 2012; FJPM et al. 2003). Along the north coast of the South China Sea and on the islands around Pearl River Delta, more than 100 shell midden and dune sites were investigated and respectively dated between 6000 and $3000 \mathrm{BP}$, illustrating the successive development of 
Neolithic near shore navigation and cultural diffusion of indigenous Southern Yue (Ou, J.F. et al. 1988; Li, Z.W. 1991b; Liang, Z.X. 1991; ZHMM 1999; Huang, C.Y. et al. 1990; GDPM 1990; Tang, C. et al. 1996; Shang, Z.T. et al. 1990). Around the Hainan island, dozens of Neolithic coastal dune and shell mound sites have also been found along the coast, dating from 6000 to 2500 years ago with the features of marine fishing and similar connotation with Pearl River Delta, presenting the prehistoric maritime culture of indigenous Island $Y i$ and Daner (儋耳) (He, G.J. 2012; FSCAT-IA-CASS et al. 2016).

The navigation activities of these prehistoric Island $Y i$ and Bai Yue were not limited in the calm nearshore water between the mainland coast and continent islands, but also crossed hundred or even hundreds of kilometers on the blue water, making their way from southeast China to Southeast Asia and eventually the Pacific archipelagos. Professor Lin Huixiang argued that the Neolithic cultures of Taiwan had been part of the cultural system of mainland southeast of China, and the result of frequent sea voyages across the Taiwan Strait (Lin, H.X. 1955, 1958b). Professor Chang Kuang-Chih also took Neolithic Fuguodun (富国墩) Culture of Jinmen island near the mainland southeast coast as the source of Tapenkeng (大贫坑) Culture of Taiwan dating to 6000-5000 years BP (Chang, K.C. 1989). The typological comparison of the Neolithic cultures from both sides of the Taiwan Strait revealed their synchronous sequences, and the rising and early growth of Neolithic cultures of Taiwan as the result of the successive emigrations of indigenous peoples from mainland to island (Li, J.T. et al. 1992). The similar Neolithic maritime cultural disseminations respectively across the Bashi Channel of the Philippines and a series of sea straits in the southeastern Asia and Pacific archipelagoes have also been reconstructed by archaeologists, presenting the prehistoric seafaring stories of proto-Austronesian and their successive emigration 5000-1000 years ago (Lin, H.X. 1958b; Chang, K.C. 1987a; Bellwood, P. 1997: 201-202; Rolett, B.V. et al. 2002).

So, for thousands of years, what were the stable and seaworthy crafts, as well as the sustained sailing force of the prehistoric indigenous Island Yi, Bai Yue and proto-Austronesian taking for their voyages across the vast ocean of the Asia-Pacific? The dugout canoe was the first candidate being considered by historians as the tool for primitive seagoing. The dugout Canoe with its lightness, singleness, and easiness to make had been created by most of the water peoples as the main prehistoric seafaring vehicle in the world. Though the dugout canoe remains of Neolithic and ancient age have been discovered in southeast China and archaeologists speculated the possibility of their applying in primitive seagoing, these single and light canoes were inherently unstable, instinctive swinging and capsizing under bad weather conditions, and obviously difficult to meet the far distant navigation on the blue waters.

The composite canoe of the Austronesian in the Pacific and adjacent areas, including both the double-hulled canoe and outrigger canoe, have been the unique and superior creation in the world nautical ethnography, which solved the difficult problem of unstableness and swinging of the single canoe in continuous sailing on the far open sea. Both the double canoe and outrigger canoe well-developed by Austronesian not only display the characteristics of lightness, flexibility of a single float acting as air chamber even submerged into water, but their composite 
structures also come into the significant lateral damp of resisting transverse swinging and capsizing for safeness. Ethnologists found that the Polynesian indigenous people could sail 145 miles a day by either double canoe or outrigger canoe, showing the strong adaptability and effectiveness of this composite seagoing boat on the violent Pacific water (Haddon, A.C. et al. 1938: 43). These composite canoes of the Pacific ethnography provide us valuable inspiration for researching the content of prehistoric seaworthy craft of indigenous Bai Yue or proto-Austronesian in the southeast coast of China.

\subsection{A Comparison of Double-Hulled "Fang Zhou" in Ancient East Asia and Double Canoe of Austronesian}

Since the seventeenth century, European navigators of Spanish, French, Dutch, British, and so on successively "discovered" the Oceania islands as a part of "Geographical Discovery", then ethnologists, artists, missionaries, colonial officials, and common travelers recorded a great amount of material cultural ethnographies of indigenous islanders, including a lot of depictions and images of the double canoes and outrigger canoes sailing in the Pacific. When the British navigator James Cook arrived at Polynesia, J. Webber, W. Hodges and other artists who accompanied James Cook voyage painted many precious sketches of indigenous sailing canoes. The most systematical investigations of indigenous sea crafts in the Pacific were carried out by A. C. Haddon and James Hornell of the Bishop Museum in the United States in 1924-1925, their records were compiled into three volumes of Canoes of Oceania (Haddon, A.C. et al. 1936, 1937, 1938). After then, Horic Horridge of the same museum conducted another specific investigation in the Indonesian archipelago and finished the book of Outrigger Canoes in Bali and Madura Indonesian (Horridge, H. 1987). These maritime ethnographies of Pacific canoes recorded in detail geographical distribution and variations in the designs, shapes, structures, and construction skills of a large number of sailing crafts as single canoe, extended canoe, outrigger canoe, double canoes, catamaran, and sea rafts, providing us the valuable information to understand the superior navigation techniques of Austronesian.

\subsubsection{The Double Canoe as a Kind of Seaworthy Boat of the Pacific Austronesian}

The double canoe of the Pacific Austronesian was the main type of composite boat lashing two dugout canoe hulls close together or a short distance apart in parallel by a number of horizontal cross beams or booms, or developed from a two-logged raft, 
on which a broad deck was usually laid, and the upper building as cabin, mast, and the sail were set.

As a kind of capable seaworthy boat in Pacific, double canoe combines both the advantages of lightness, portability of canoe, and the structural performances of stability of resisting transverse swing and capsizing of the composite and extended hulls, as well as the increasing of carrying capacity. These composite hulls made the simple canoe great seaworthy for maritime transportation across the open sea, which could be a seagoing passenger boat and fishing vehicle with spacious platform and roof built on connective booms, or a war fleet with thin and long hull equipped with horizontal deck for warriors and sails for oceanic fighting.

After arriving to the south Pacific islands, the western navigators met different types of double composite canoes. One was equal-sided hulls double canoe craft which composited two symmetrical hulls of equal size and lashed together by means of cross beams or booms, usually with the mast stepped at forward position of the amidship forming definite head and stern, mostly discovered in the Polynesia and south of Micronesia Islands. The second type was the disparate-sided hulls double canoe which composited two hulls with different form and size, the small hull was usually made fine and pointed functioning as a float of the whole raft, with the mast stepped at the amidships and able to sail either end forward, mostly developed in south of Melanesia Islands.

The equal-sided hulls double canoe were usually sketched in the early Pacific ethnographies of seventeenth and eighteenth centuries. The tongiaki was a kind of famous double canoe used in Tanga till the end of eighteenth century before it was substituted by disparate-sided hulls one of Fiji. W. C. Schouten and A. J. Tasman successively came across this craft and made a drawing record (Fig. 7.1a and b). In Tasman's work, a tongiaki under full sail in the Gulf of Tongan in 1643 was illustrated, two fine dugout canoes were connected in parallel at an adequate distance under a broad deck, on which a round roof cabin was set, a bonfire pile was made in front of the platform, and an Oceanic lateen sail with sprit mast was stepped at fore part (Haddon, A.C. et al. 1936: 267). In 1778, J. Webber, the painter accompanying Jame Cook's voyage depicted a sketch of a double canoe of war fleet sailed by the Hawaiian indigenous warriors. The shape of the two dugout hulls was slender and soundly strong, connecting together with certain intervals by a few of booms. The mast was vertically stepped above the second boom at the midway between hulls and a typical crab-claw spritsail was set, getting strong pulling power for speedily going (Haddon, A.C. et al. 1936: 6; Fig. 7.2).

The double canoe with disparate-sided hulls was typically developed in Fiji island of south Melanesia represented by the ndrua. The craft usually consisted of two unequal dugout hulls, lashed horizontally in parallel by crossing booms on which a large platform was set. The sailing mast was stepped at the amidship of a large hull, while the small hull was made in reduced size with pointed ends, enabling the craft sail forward on either end (Haddon, A.C. et al. 1936: 321).

Since 1970s, Pacific anthropologists and navigators engaged in reviving the original sailing techniques of Polynesian composite canoes. The Polynesian Voyaging Society successfully organized the non-instrument sailing of the double 
a

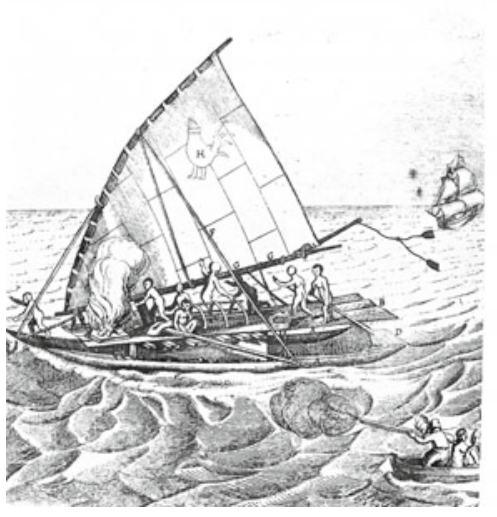

b

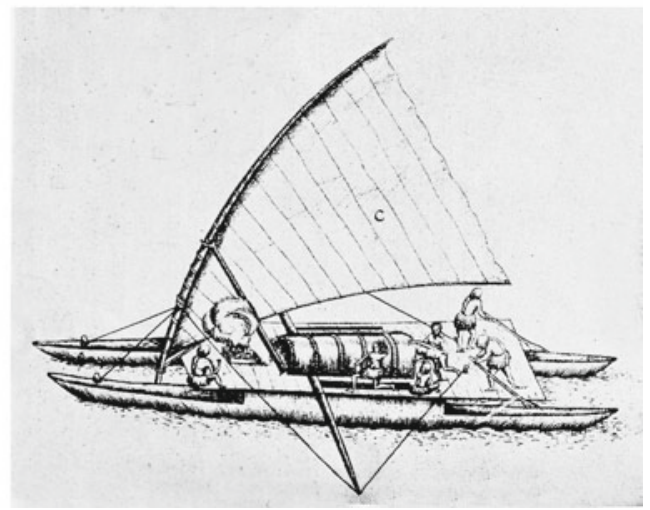

Fig. 7.1 Early double canoes tongiaki of seventeenth century in Tongan (after A.C. Haddon, et al. 1936: 266-267, Fig. 189-190). a A tongiaki seen off Tafahi Island of Tongan in 1616 recorded by W.C. Schouten. b A tongiaki seen in the Gulf of Tongan in 1643 illustrated by A. J. Tasman

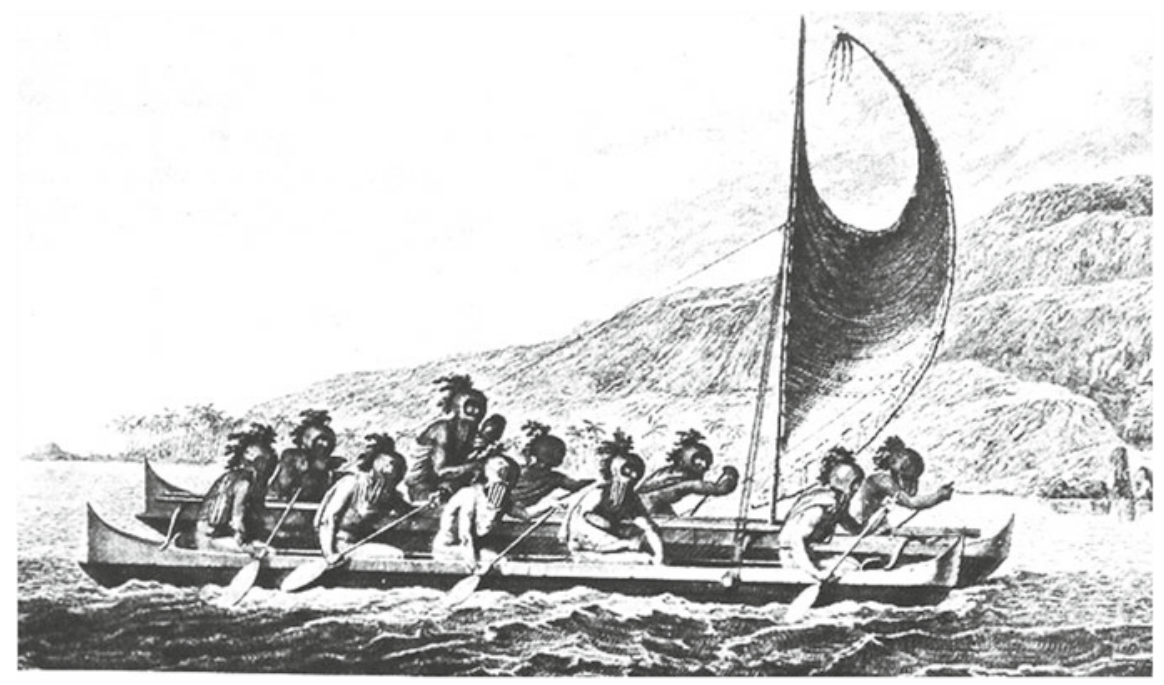

Fig. 7.2 The war fleet of Hawaiian double canoes depicted by J. Webber on Jame Cook's voyage (after A.C. Haddon, et al. 1936: 6, Fig. 1)

canoe Hokule'a between Hawaii and Tahiti island and several other Pacific voyages, stressing the prominence of double canoes in Indigenous community of Pacific (Finney, B. 2003: 9-14, 110-130; Finney, B. et al. 2007'; Fig. 7.3).

Double canoe with both of its portability and the stability met the long distance sea crossing under the prehistoric shipbuilding technology of dugout canoe. It was regarded as a distinctive creation of Pacific islanders. "A contrivance so simple and 


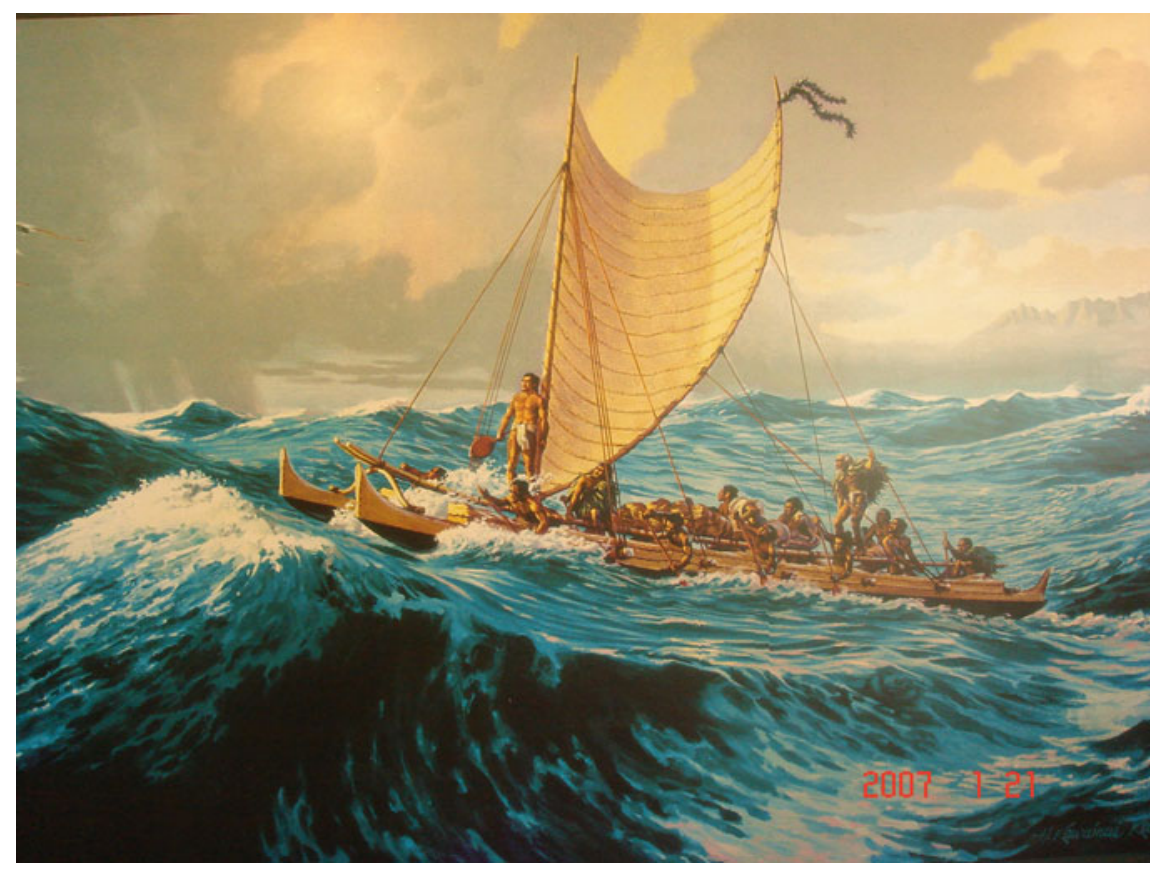

Fig. 7.3 A poster of Hawaiian double canoe voyage in the Hunauma Bay Nature Preserve of Hawaii, 2007

practical for procuring stability and increased carrying capacity would have been adopted everywhere, but as matter of fact, it belongs almost exclusively to Indo-Pacific area" (Haddon, A.C. et al. 1938: 43). Nevertheless, along the coast of East and Northeast Asia, the same cultural heritages were also recorded in historical literatures and archaeological records, showing potential maritime cultural interaction in Asia-Pacific region since prehistory.

\subsubsection{The Historical Records and Archaeological Discoveries of Double-Hulled Craft "Fang Zhou" in Eastern Asia}

In the regional comparison research, A. C. Haddon and J. Hornell noticed that the indigenous Eskimo along the coastal region of Northeast Asia occasionally tied two kayaks together as a temporary means of ensuring stability in their seafaring (Haddon, A.C. et al. 1938: 43). Another case of ethnographical double-hulled boat was recorded along the Hokkaido coast of Japan, the ancient indigenous Emishi boat man, the Ainu, also developed and used the double canoe "Fang" (舫) in their 

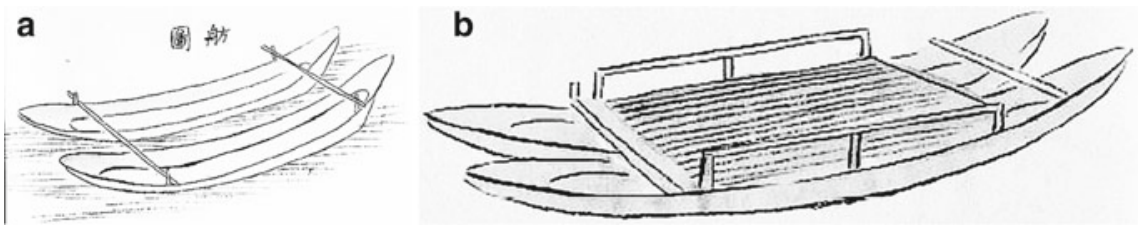

Fig. 7.4 The double canoe "Fang" (舫) of indigenous Ainu along Hokkaido coast of Japan (after T. Matsuura, 1845:舫图)

offshore navigation (Fig. 7.4). According to their historical literature of An Illustration of the Wealth and Material Culture of Ainu People (Xiayi Jiacai Tushuo 虾夷家财图说), the Ainu Fang was sketched as composition of two dugout canoes connected by two cross boom on which the platform and side rail were set (Matsuura, T. 1845). The Ainu islanders as the main indigenous population in ancient Emishi region was identified as the Malay-Polynesian branch of Austronesian. Therefore, the Fang of the Ainu people are of great significance in understanding the distribution and intrinsic interaction of the early seafaring boat of double canoe in broader Asia-Pacific region.

The using the double-hulled boat "Fang" in ancient China was also recorded in historical documents. The Chinese character of 舫 (Fang) is a polysemous word and generally referred to a building on water imitating the boat shape in ancient times. However, the original meaning of Fang was not the boat-shaped house on the water, but the "parallel boats" which was quite common from Zhou to Han dynasties 2000-3000 years ago. "Biography of Zhangyi" (张仪传) of the Records of the Historian (Shiji 史记) states: "A Fang boat can carry fifty warriors with food enough for three months and float down the stream with the speed of about three hundred $l i$ (one $l i$ is about five hundred meters) a day." This Fang was interpreted by Sima Zhen (司马贞) of Tang Dynasty in “Annotation” (索隐) of the book as "two boats connected in parallel" (Sima, Q. 1959: 2783).

The section of "Explanation of Water (释水)" in Literary Expositor (Er Ya 尔雅) describes the rules on using boats in the ritual hierarchy of the Zhou Dynasty. "The emperor uses a floating bridge connected by seven boats, a duke or prince (诸侯) uses a ship connected by four boats, a senior official Dafu (大夫) uses a double-connected boat, a junior officer Shi (士) uses a single boat, and a common people uses a raft" (Ruan, Y. 2009: 5697).

The similar double-hulled boat ethnographical heritages were also witnessed and recorded along the coastal of southern China. The Long Chuan (泷船, 泷舡) boat employed in the coast area of Guangdong during the Qing Dynasty was one of this important legacy in Chinese maritime ethnography. The section of "Boat" (船语) of A New Introduction to Guangdong (Guangdong Xinyu 广东新语) by $\mathrm{Qu}$ Dajun (屈大均) of the Qing Dynasty records: “The Liulong (六泷) River was also called Wuxi (武溪) River in the ancient time, in which the water was running very fast and dangerous, and was regarded as unfavorable water for sailing by disciples of general Mayuan (马援) of Han Dynasty. For the current of it was rapid and 
rushing, the boats were usually stranded and the single boat capsized, the composite double-hulled boats were usually employed...This kind of composite double-hulled boat was made by two dugout canoes being connected together as a floating raft... The local people called this composite double boat as Long Chuan boat, or Xialai Chuan (下濑船) boat which originated from the navy boat of general Xialai who defeated Southern Yue state in early Han Dynasty" (Qu, D.J. 1985: 484-485). This type of double-hulled Long Chuan (泷船) boat were continuously employed in Lingnan (岭南) region for a long time and commonly recorded in ancient literatures from Tang to Qing dynasties. For example, "Long Chuan (泷船) boat anchored beach" in Yuanzhen (元稹) poem “Accompanying Friends Touring to Lingnan” in Tang dynasty, "Getting off the Long Chuan boat in Autumn day" in Feng Yinqi (凤尹岐) poem “Presenting Bless to Friend Yinggui (应奎) to Be Official to Guangdong" in the Ming Dynasty, and "Long Chuan boat came from an area beyond the Nanling in early Autumn season" in Du Jie's (杜岕) poem “Blessing Friend Huangzi (黄子) Leaving Off Chaozhou in Guangdong” in Qing Dynasty, all indicating that this type of Long Chuan boat has a long history of development along this coastal region of southern China.

Although there has still no definitely remains of seafaring double canoe of prehistory and early ancient history in China, a double-hulled boat of Sui Dynasty (AD581-618) was discovered in 1975 on the beach of the east bank of Zehe (泽河) River in Pingdu (平度) county of Shandong Province, providing the significant clue of utilizing the seagoing double canoe along coast region of ancient China (Fig. 7.5). This double-hulled boat with a remnant of 20.24 meters long was connected in parallel with two longitudinally extended canoes, the bow and stern lost a bit and was reconstructed to 23 meters. The two canoe hulls were respectively the extended canoes with $U$ shape cross section and were longitudinally connected by three sections of bulky trunk dugout canoes. The two paralleled extended canoe hulls were connected by 20 pieces of crossbeams across the symmetric hole on the two sides of the hulls, which were covered by deck board. On the rear board remained 3 pairs of symmetric stakes as the component of the boat house. The carrying capacity of this double canoe was evaluated to 23 tons. Referred to the sailing practice of double canoe of Austronesian, the size and structure of Pingdu double-hulled boat would be a qualified seagoing craft if it was equipped with sailing facilities. Interestingly, this double canoe found on the ancient beach was made of Cinnamomum camphora and Liquidambar formosana hance, both are typical varieties of endemic tree special of environment in the southern China, indicating that it might be the remains of northward seafaring boat along the coast of China (SDPM et al. 1979).

Another large canoe of Song Dynasty excavated in 1991 in Jindo (珍岛) county, South Jeolla Province (全罗南道) of South Korea, was speculated to be a part of the remnant of double-hulled seagoing boat. It was a longitudinally extended canoe and composited by three dugout canoes made of camphor connecting together by mortise-tenon joint and iron nail, with residual length of 16.85 meters. Eight pieces of Chinese copper coins of the Song Dynasty were placed in the "longevity hole" at the joint of the canoes, identified as the southern Fujian shipbuilding custom, and 


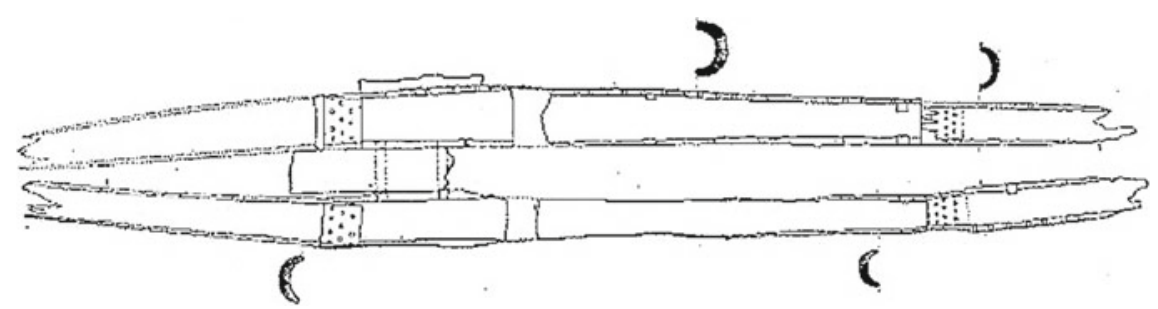

Fig. 7.5 A double-hulled boat of Sui Dynasty (AD581-618) unearthed in Pingdu (平度) of Shandong

two-hole mast step was set at the amidships of the canoe (Fig. 7.6). It is determined by the $\mathrm{C}^{14}$ dating to $710 \pm 30 \mathrm{BP}$, and might come from the south of China in the Song Dynasty (Yuan, X.C. 1994).

The asymmetrical plan with longitudinal curve of outboard of two sides of this Jindo canoe remnant, that is the straight stroke-side and the normal arc shape starboard is notable. This asymmetrical shape in water line is quite different from the normal form of a single canoe, but a part of composite boat of double canoe or single outrigger canoe, which is consistent with some cases of double canoe in Pacific, such as the asymmetrical plan of the starboard of Fijian double canoe ndrua (Haddon, A.C. et al. 1936: 321). So Jindo canoe is speculated as the starboard hull remnant of a composite double canoe or a single outrigger canoe with float connecting in the left of the hull.

In a word, as an excellent contrivance and well-developed seafaring craft of Austronesian, the double canoe might also be employed in East Asian seas in medieval age. These historical heritages of double-hulled boat in Japan, Korea, and coast of China are most likely related to the maritime history of the prehistoric Island $\mathrm{Yi}$ and Bai Yue and closely connected to the Pacific Austronesian, with considerable historical value in research of maritime cultural relationships in AsiaPacific.
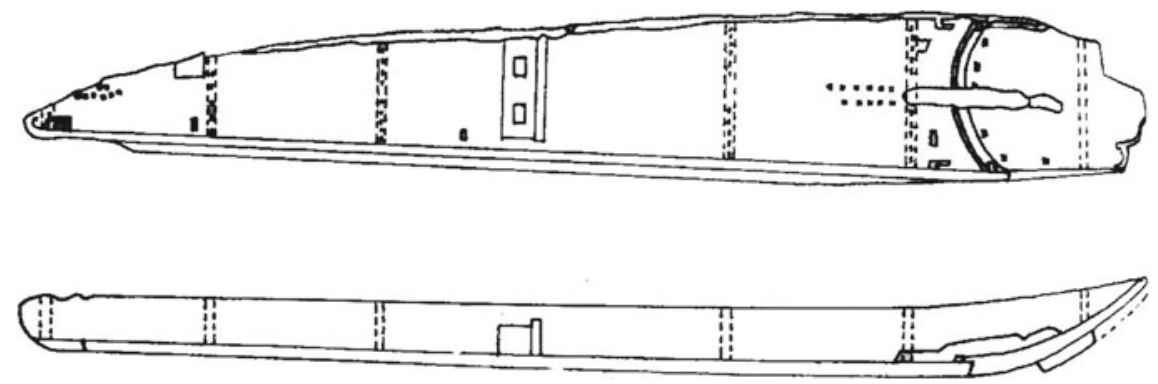

Fig. 7.6 The remnant of a suspected double-hulled seagoing boat in Jindo of South Korea 


\subsection{The Heritage of "Mangka" and "Mother-Son Boat" in South China and Pacific Outrigger Canoe}

According to modern ethnographical literatures, the outrigger canoe with the sail has been another seaworthy craft of the indigenous navigators on the Indo-Pacific oceans for hundreds or even thousands of years. Further investigations in southern China revealed a number of similar cultural heritages of outrigger boats, such as the "Mangka" canoe in Taiwan, "Mother-Son Boat" in the minority Miao (苗) village in Guizhou (贵州), and the Neolithic canoe remains in Kuohuqiao (跨湖桥) site in Zhejiang. They are the valuable "cultural fossils" for us to redraw the new blueprint of prehistoric outrigger distribution in the south coast of China.

\subsubsection{The Variants of Austronesian Outriggers in Indo-Pacific Region}

An outrigger canoe is a canoe joining "outrigger" of small canoe-shaped float(s) on one side or on both sides, respectively being a single outrigger or double outrigger (Haddon, A.C. et al. 1938: 15-19; Fig. 7.7).

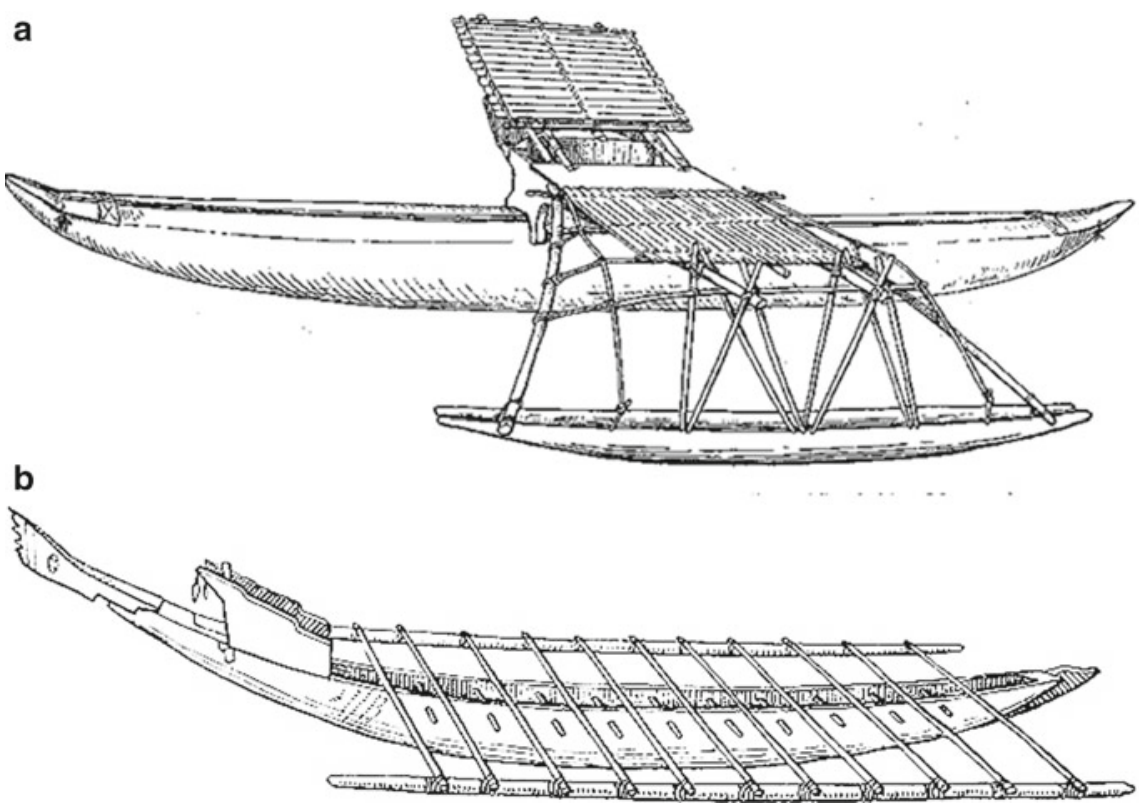

Fig. 7.7 Sketches of two types of the Pacific outrigger canoe (after A.C. Haddon, et al. 1937: 47, 326, Fig. 30, 188). a A model of single outrigger tepukei of San Cruz Islands (Cambridge Museum collection). b A model of double outrigger tababeri of Ansus Island in New Guinea (originally provided by De Clerq and Schmeltz, 1893) 
As composite seagoing canoe by boomed out floating outriggers to be the balance on each side of a dugout, the double outrigger of Pacific was detailed in Euro-American ethnographical literatures. In Indonesian, the double outrigger was highly developed and varied in sizes, styles, structures, and functions in different areas of different periods, for example, the large outriggers as the Indonesian coastal trading vessel vlerprauw, Sulawesi and Moluccas warrior carrier kora kora, large Javanese fishing boat perahu payany, the Sulu island houseboats Bajau, and the Balinese heavy goods carrier Jukung Gede (Horridge, H. 1987: 19-23). Most of the Indonesian double outriggers are distinctive in bent curves or spliced booms directly lashed or inserted into float.

A single outrigger canoe is a type of composite canoe joining the dugout hull in one side with a float by booms, forming the light, balance, and stable seagoing boat. As the recordings of early ethnologists in Fiji, the single outrigger canoe thamakau was composited with a wide platform between the wooden dugout and the float on one side of the hull to accommodate the crew, passengers, or cargo, equipped with a great lateen sail to provide tremendous driving power for the light canoe, which fully demonstrates the excellent performance of the Pacific single outrigger (Haddon, A.C. et al. 1936: 315; Fig. 7.8). In Marquesas of Polynesia, both double canoe and single outriggers canoe were highly developed. In $1774 \mathrm{~W}$. Hodges drew indigenous single outriggers on Vaitahu island in Tahuata, Marquesas Islands, showing the early style of single outriggers with projecting flat prow and curved backward, which were equipped with lateen sails (Haddon, A.C. et al. 1936: 35).

The types of attachment were the important technological connotation of outrigger construction, which varied greatly in different areas of the Pacific. The float of outrigger was a log of wood or length of bamboo with shape of round log, round or flat canoe shape boomed out on one or both sides of the hull as a counterpoise. Two, three, four, or more booms were used to connect the hull and outriggers, with the shapes of straight or various kinds of curved pieces such as bent curve, elbowed, arc, or S shape. The booms were lashed horizontally across the holes on the upper board or the wash strake of the hull, or bound with inserted ribs and bulkhead frame of interior hull, connecting with onboard deck and platform structure. The outrigger attachment also varied regionally, the indirect connectives lashed or inserted into the vertical or slanting sticks on the float, which mainly applied in three Pacific archipelagoes, and the direct connectives by bending the distal extremities of booms curved or elbowed shape and lashing or inserting into float, which mainly applied in Indonesia and Indian Ocean (Haddon, A.C. et al. 1937: 47, 1938: 23-26, 28, 31-32).

For the historical reasons of cultural change and indigenous migration, the two types of outrigger canoes presented different distributions in Indo-Pacific region. Double outrigger mainly distributed in most of Indonesian islands, the adjacent west of Melanesia, the northern coast of Australia, Madagascar, and Comoros of east Africa, while single outriggers are widely distributed in Polynesia, Micronesia, Melanesia, New Guinea, and some places of Indonesia, Madagascar, Comoro of east Africa, south Indian, Ceylon, Maldives, Andaman, Nicobar of south Asia, almost in all indigenous Austronesian societies. A. C. Haddon and James Hornell believed that 


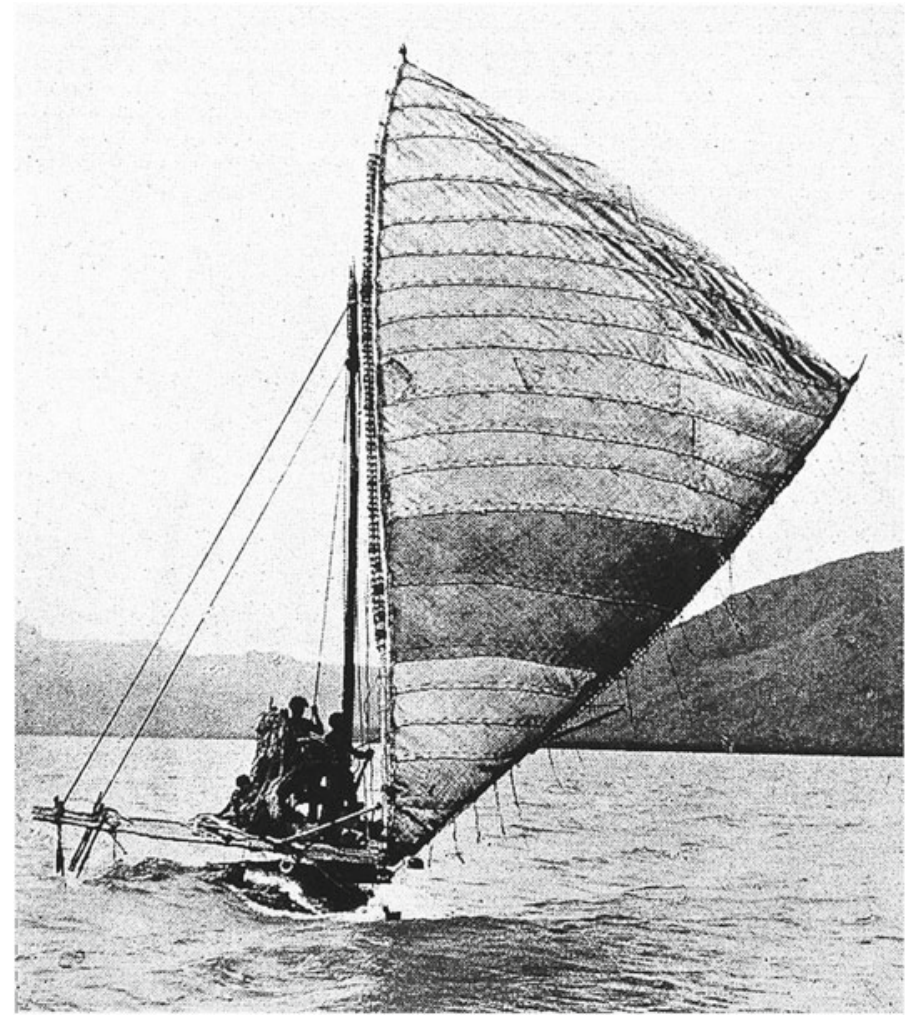

Fig. 7.8 The single outrigger canoe thamakau in Fiji (photograph by A. M. Hocart, after A.C. Haddon, et al. 1936: 315, Fig. 232)

the emergence of double outriggers was logically earlier and far less seaworthy than single outriggers, and double outriggers had been the original form of outrigger canoes (Haddon, A.C. et al. 1938: 15-21; Kapitan, G. 1987). Though there is no archaeological shipwreck of early outrigger to show its origin, the Barabudur stone sculptural relics in Java provide the oldest evidence of the outrigger canoe in Indonesia. Eight sailing boat carvings including five outriggers, all in double, were carved in this early Buddhist shrine dating to the beginning of the Christian era to the tenth century. So the double outrigger might originate at least two thousand years ago in Indonesia (Haddon, A.C. et al. 1938: 17; Kempers, A.J.B. 1959: 47, plate 78). The single outrigger may have been the developed form and subsequent modification of the double outrigger by eliminating one outrigger of it to get an easier and safer vessel. Practically, a single outrigger not only had enough stability to resist transverse damping force but also had better structure and lightness in seagoing performance. It is generally considered that indigenous people of Polynesia and Micronesia have not developed double outriggers in the late historic times. The differentially spatial distribution of the single and double outriggers reflects the 
process of the spreading and dispersal of double outriggers from the Indonesian eastward to Melanesia at early stage of their oceanic migration, and outgrowing into new stage of single outrigger in Micronesia and Polynesia Islands.

\subsubsection{The Ethnographical Discovery of the Double Outrigger Mangka and Mother-Son Boat in South of China}

For more than half a century, the composite canoe recorded in the Pacific ethnography, especially the double outrigger as the early and primitive stage of the outrigger canoe has attracted a lot of attention of ethno-archaeologists in Eastern Asia. Through the comparison of ancient historical documents and Pacific ethnographic records, Professor Ling Chunsheng searched for a number of outrigger canoe materials in ancient Chinese literature. He noted that in the Qing Dynasty, the Mangka in the aboriginal ethnography of Taiwan was the double outrigger. In the Vol. six of "Custom of Aboriginal Fan (番俗考)" in the Records of Mission Trip to Taiwan (Taihai Shichai Lu 台海使槎录), Huang Shujing (黄叔璥) recorded that "Mangka is the dugout of the single log and joined with planks on two sides by lashing with rattan" (Huang, S.J. 1936: 130). Chen Shujun (陈淑均) also recorded in the Vol. five of "Custom of Aboriginal Fan (番俗考)" of his Chronicle of Kavalan County (Gamalan Tingzhi 噶玛兰厅志) of Qing Dynasty that "the Aboriginal Fan use ferrying canoe called Mangka or Mengxia (艋舺), Mangge (蚲 葛)... which is dugout a single log and joined with planks on two sides by lashing with rattan" (Chen, S.J. 1984: 167). We agree that these depictions of the dugout canoe with lashed planks on its two sides might be the outrigger canoe. Furthermore, the ethno-linguistic investigation proves the similarity and connection of Taiwan aboriginal Mangka with the Pacific outrigger. The Mangka in Taiwan aboriginals as a branch of Austronesian is similarly pronounced with the outrigger in the Pacific Austronesian, such as the outrigger canoe in Indonesia, the Philippines, Micronesia, Melanesia, and Polynesia were also commonly pronounced wangka, waka, and slightly changed in the New British Isles as haka, in the Bougainville Islands as vakas, vakati, hakas, and in the New Hebrides as angge, wanga, nawangk and so on (Haddon, A.C. et al. 1938: 71). This important witness of linguistic further indicates that Mangka of Taiwan aborigines in the Qing Dynasty was not a small single canoe but the composite double outrigger similar to that of the Indonesian and Pacific Austronesian, which is of great significance in exploring the maritime cultural integration of the Asia-Pacific since prehistory.

The most typical heritage of outrigger canoe remained in the south of China is the "Mother-Son Boat" of minority Miao village in Shidong (施洞) town of Taijiang (台江) county, southeast Guizhou. From May 24 to 26 in the lunar year of 2008, during the annual Dragon Boat Festival of Miao ethnic, the author made a special trip to Shidong town, surveying the shape, structure, and building technique 
of the Miao dragon boat known as the "Mother-Son Boat". We realized after that this "Mother-Son Boat" was definitely a unique double outrigger similar to that of Austronesian in Indonisian, and the cultural fossil of the prehistoric "outrigger canoe" in south China. It provides the solid evidence for exploring prehistoric seafaring craft tools of proto-Austronesian and Bai Yue indigenous people in south China (Wu, C.M. 2008a).

During the Dragon Boat Festival, most of Miao villages around Shidong participate in paddling dragon boat competitions (Fig. 7.9). The shapes and scales of these dragon boats from each village are largely identical but with minor differences, characterized by the composite feature of "Mother-Son Boat" which consisted of one big and two small canoes lashed together. These composite dragon canoes mostly were built after the 1980s, and the big Mother canoe no longer was constructed with a whole log for the reason of lack of big tree but composed of several sections of logs still maintaining the characteristics of a dugout canoe. They were consistent with what was recorded in the Accounts of My Experience in the Miao Territory (Miaojiang Wenjianlu 苗疆闻见录) that “the boat is dug out of a large log...with the bow of a dragon head and stern of a phoenix tail shape. The hull is capable of containing more than twenty persons who row with short paddles to make the canoe going fast as flying" (Xu, J.G. 1997: 171). All of the Mother-Son Boats were moved to the Qingshuijiang (清水江) River to participate in the festival, and after then were taken apart and kept in specific dragon canoe sheds of their own village (Fig. 7.10).

Taking the dragon canoe of Pingdiying (平地营) village as an example, the length of the Mother canoe is $23.6 \mathrm{~m}$, the cross section of the amidships hull approximately round shaped and the widest part of it is $0.6 \mathrm{~m}$, the depth of inboard of the bow is $0.54 \mathrm{~m}$, and that of the amidships $0.46 \mathrm{~m}$ and the stern $0.38 \mathrm{~m}$, with the undivided inboard of the hull. The Son canoes on both sides are $14 \mathrm{~m}$ long, $0.38 \mathrm{~m}$ wide, and $0.37 \mathrm{~m}$ deep in the middle. Five rows of horizontal booms are set

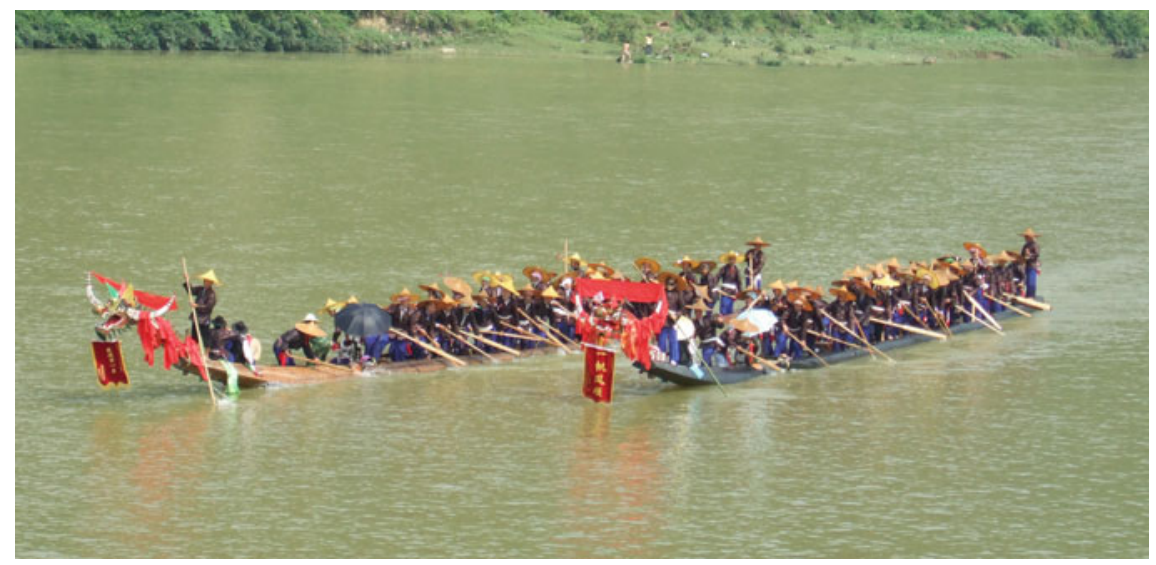

Fig. 7.9 The dragon boat competition of Miao villages around Shidong during the Dragon Boat Festival 


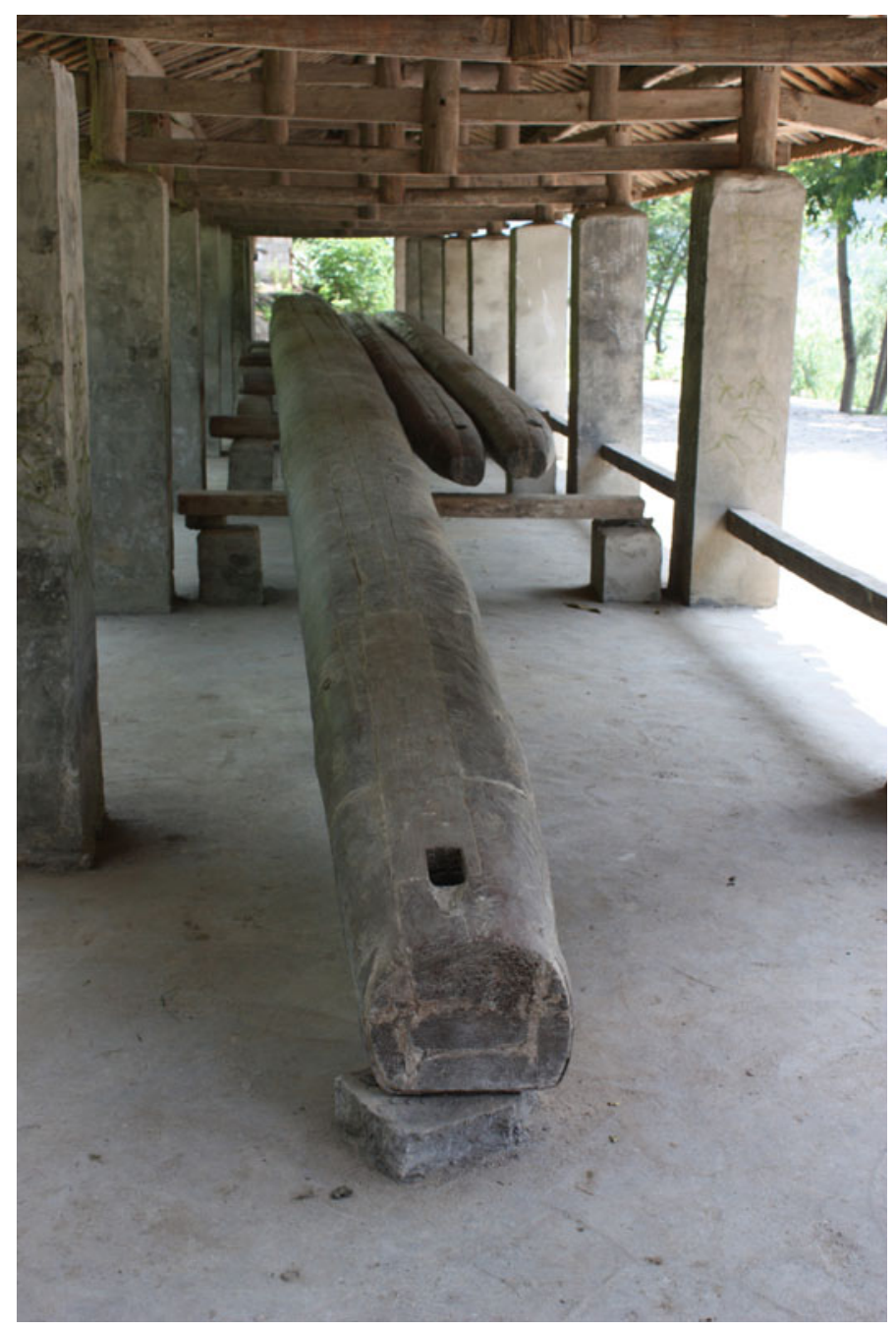

Fig. 7.10 One "Mother" hull and two "Son" floats of a "Mother-Son Boat" preserved in the boat shed of Miao village in Shidong

up across the upper board of the middle section of mother canoe, connecting two canoes on both sides by tenon-mortise joint or bamboo strip lashing. No metal bolt, nail, and perforation in the hull are used for the connection of Mother hull and Son floats, highlighting its primitiveness and originality. The bow of the Mother canoe is ornamented with carved wooden dragon heads with horn-shaped ears by bolts and strip lashing (Fig. 7.11).

The shape, size, and structure of the dragon canoe of Baiziping (柏子坪) village is similar to that of Pingdiying, except for the little difference of the connectives 
a

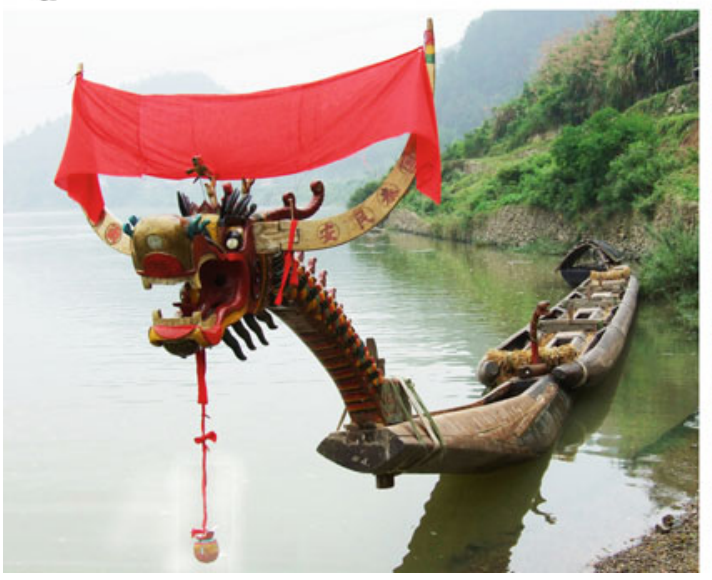

b

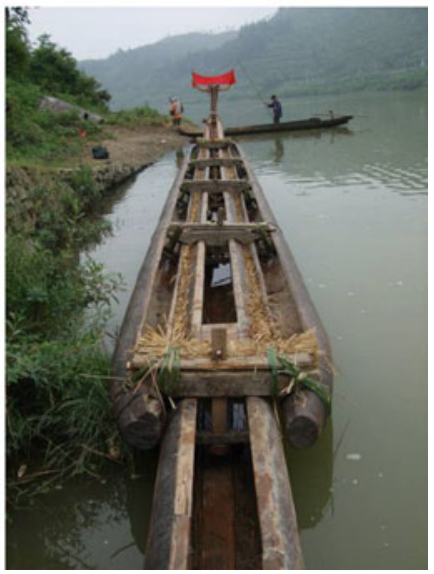

Fig. 7.11 The "Mother-Son Boat" of Pingdiying Village

between the Mother canoe and the two Son canoes. The length of the Mother canoe is $23.26 \mathrm{~m}$, the cross section of the amidships hull is almost round shaped and the widest part of it is $0.67 \mathrm{~m}$, the depth of inboard of the bow is $0.53 \mathrm{~m}$, and that of the amidships is $0.44 \mathrm{~m}$, with undivided inboard of the hull. The Son canoes on both sides are $14.53 \mathrm{~m}$ long, $0.28-0.37 \mathrm{~m}$ wide, and $0.36 \mathrm{~m}$ deep inboard of the amidships. Five rows of horizontal booms are set up across on upper board in the middle section of the Mother canoe, jointing with Mother canoe by full tenon-mortise structure, and with two Son canoes by steel bolts. The flat iron hoops are applied to strengthen the hull of the Mother canoe around outboard at positions of each boom. The bow of the Mother canoe is also ornamented with carved wooden dragon heads with horn-shaped ears by bolts and flat iron hoop (Fig. 7.12).

Compared with double outriggers in Southeast Asia and the Pacific, the Mother-Son Boat of Shidong shares basic structural commonalities and the same

a

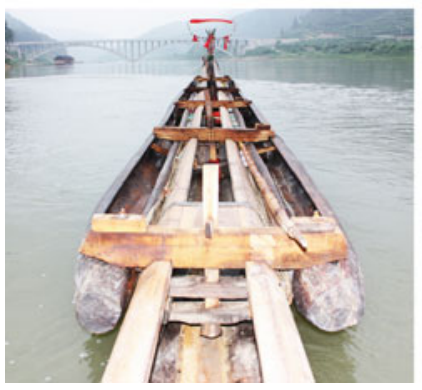

b

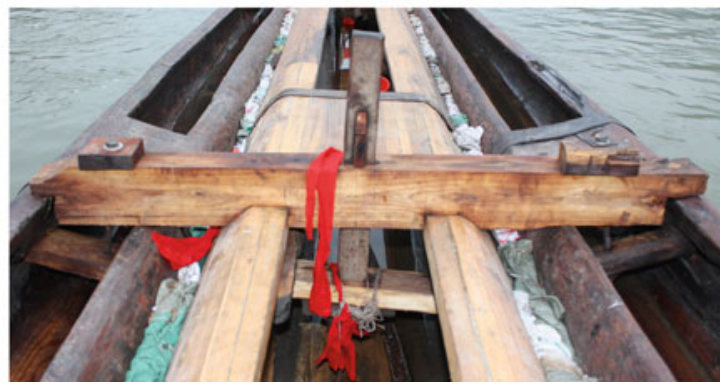

Fig. 7.12 The "Mother-Son Boat" of Baiziping Village 
designing motivation of stability for resisting transverse swinging primitive dugout canoe. They are the same type of primitive watercraft in the shipbuilding history of the world.

Firstly, Both the Mother-Son Boat of Shidong and the outrigger canoe of Pacific applied the similar composite form and structure of canoe, which connecting one or two small canoes or float to one or both sides of a large canoe. This lateral composite form of canoes was designed to increase the horizontal damping force and vertical stabilities of the hull to resist transverse swing of the craft underway. They exactly share the same designing concept of the composite layout with main hull and side float(s). The Mother-Son Boat of Shidong is actually a special kind of double outrigger, forming a composite form of one "Mother" and two "Sons", while Austronesian outrigger canoe includes both double outriggers with one large canoe hull joining two small floats or simplified canoes and single outrigger with a large canoe joining a small float or simplified canoe. According to the previous analysis on the historical development of Pacific outrigger from the double outrigger mainly distributing in Indonesia islands and adjacent regions of the Southeast Asia to the single outrigger widely distributing in Indo-Pacific region, the Mother-Son Boat of Shidong is consistent with the original and early stage of the outrigger canoe. The prominent difference of Shidong "outrigger" is that the Son canoes on both sides are closely clinging to the Mother canoe by the short booms, while the outriggers of Pacific are generally arranged an adequate distance between the main hull and the side float(s) with connectives of long booms. These two forms of composite boats are respectively adapted to different environments of the inland river and the open sea. The Mother-Son Boat of Shidong with relatively small lateral damping force is more suitable for narrow and somehow stable river environment, while Pacific outrigger canoe with greater lateral damping force is undoubtedly more suitable for the vast, windy, and wavy oceanic environment.

In fact, as early as more than half a century ago, Austrian archaeologist Heine-Gelden also found that in the Mekong River and the upper reaches of the Irrawaddy River of the Southeast Asian Peninsula, the river boats usually attached double outriggers to their sides to keep balance and to increase buoyancy, and the floats of the side canoe were made of several bamboo rods or bundled reeds lashed to the hull by very short booms (Haddon, A.C. et al. 1938: 21). He argued that these inland boatmen as the proto-Austronesian had lengthened the booms of the primitive outrigger on the rivers and innovated a new form of seaworthy double outrigger to meet the seafaring after they migrated into the coast of Malay Peninsula. The Mekong River originates from the plateau of southwest China, it is quite possible that the outrigger canoes on the Mekong River share the same source with the heritage of prehistoric canoes in south China as Mother-Son Boat in Shidong.

Secondly, Both Mother-Son Boat of Shidong and outrigger canoe of Indo-Pacific region attach floats to the main hull with a number of laterally connecting bars or planks. On Mother-Son Boat of Shidong, there are generally five booms directly connecting the Mother and Son canoes with tenon-mortise structure or lashed with ropes of bamboo strip, which are similar with various ways of 


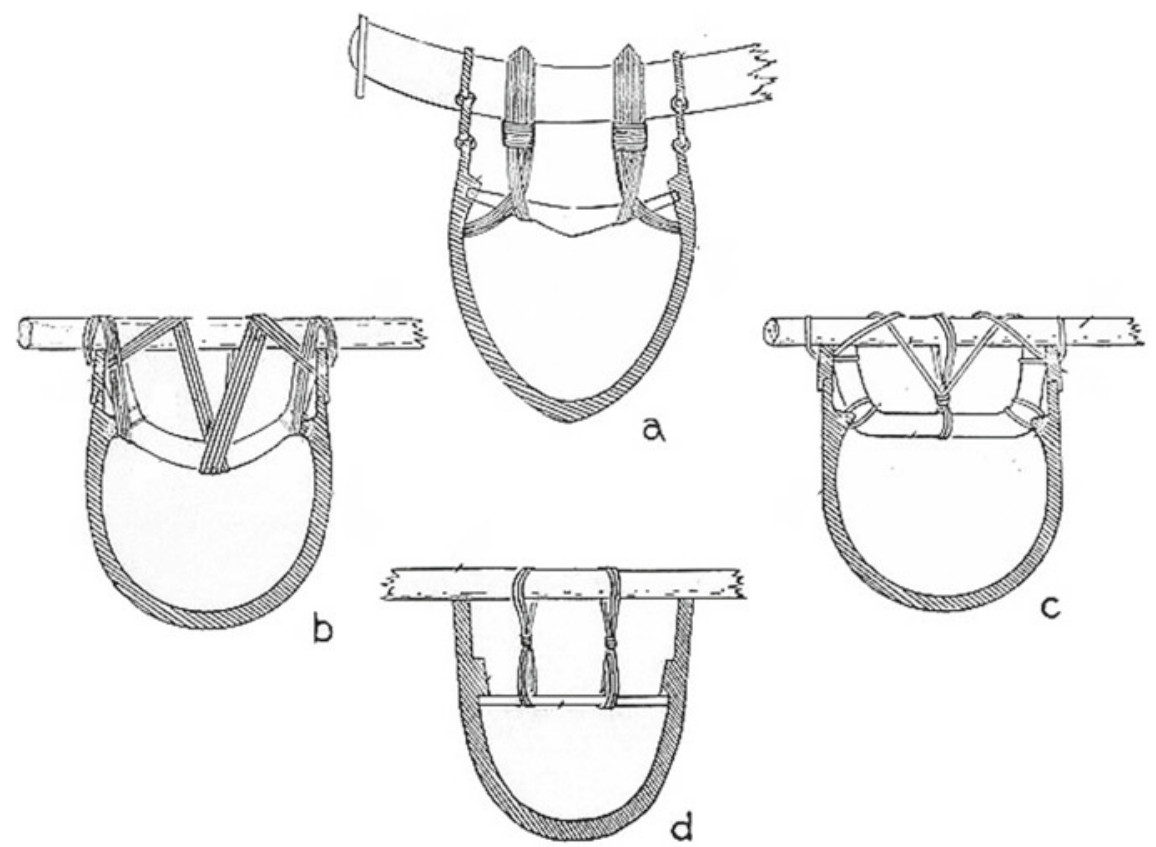

Fig. 7.13 The connective ways of lashing booms into the hull of a composite canoe in Pacific region (After A.C. Haddon, et al. 1936: 11, Fig. 5)

connective used for Pacific outrigger, including both the directly lashing or inserting booms into the hull and float, and the indirectly lashing or inserting booms into the vertical or slanting sticks on the float (Figs. 7.13 and 7.14).

Lastly, both the interior hull of Mother-Son Boat of Shidong and most of the Pacific outrigger canoe are in the form of open hold without subdivision, constituting the early and primitive feature of the ship technology as the most dugout canoes in the world. The hold of Shidong's Mother-Son Boat is narrow and long relating to the special function of the dragon boat competition. According to oral story of local Miao people of Tanglong (塘龙) village, the interior hold of Mother-Son Boat in ancient times were relatively large inboard capable of carrying passengers, cargoes, and livestock, similar to the Pacific composite canoe which the open platform was usually built on the booms for crew and passenger accommodation, carrying cargo or even keeping livestock.

The identity of Shidong Mother-Son Boat and the Pacific outrigger canoe provides a valuable perspective on investigating and searching the prehistoric seagoing crafts between south of China and the Pacific via Southeast Asia. The Taijiang is located in Leigongshan (雷公山) district, southeast Guizhou, one of the important watershed between the Duliujiang (都柳江) River of upper reach of Xijiang (西江) 
a

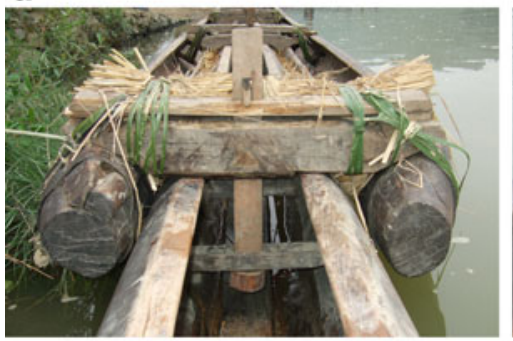

C

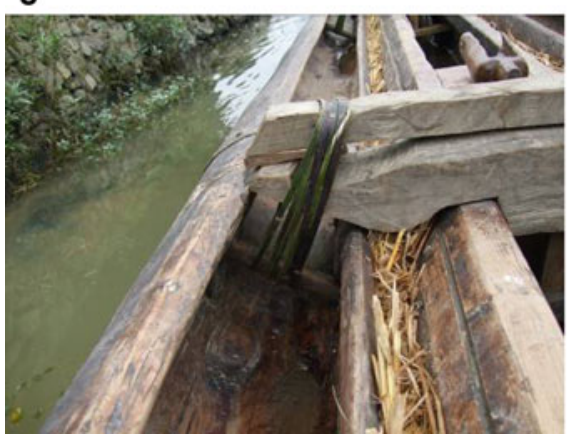

b

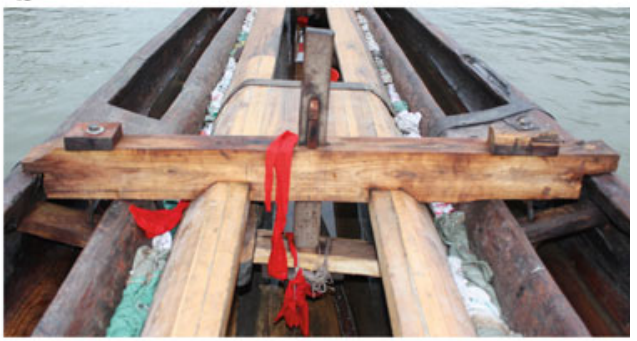

d

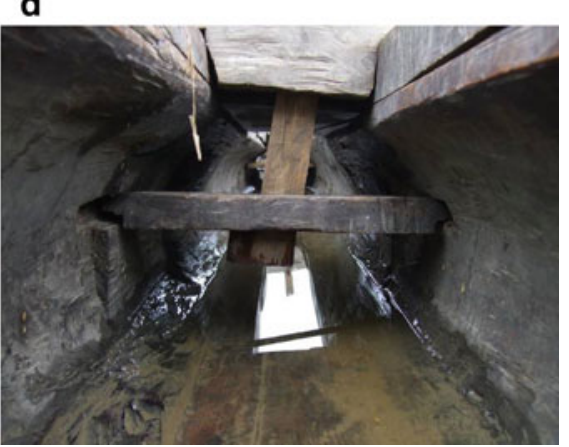

Fig. 7.14 The connective ways of lashing booms into the hull and floats of a "Mother-Son Boat" in Shidong

of the Pearl River system, and the Qingshuijiang River of the upper reach of Yuanshui (沅水) River in middle reaches system of the Yangtze River. Shidong wharf was still the transportation and trade center along the water route from Guizhou to the middle and lower reaches of the Yangtze River not long ago. The upper Duliujiang River Valley had been the important water route for the migration of Shui (水), Dong (侗) as the lineal descendant of Western Ou (西瓯), Luo Yue (骆 越) of two main branches of Bai Yue in the west region of Lingnan, who migrated westward after the demise of Bai Yue during Han and Tang dynasties. The upper Qingshuijiang River Valley had been the water route for the early Miao people moving upstream along the Xiangjiang (湘江)—Yuanshui-Qingshuijiang rivers into mountainous Guizhou. In a word, The ethnic cultural composition in southeastern Guizhou between the Qingshuijiang and the Duliujiang river basins has been very complicated and multivariate since the prehistory and early history, with closely and deeply cultural exchanges between Bai Yue and Bai Pu (百誉) ethnicities. Therefore, as a special type of outrigger canoe, the Mother-Son Boat of Miao ethnic in Shidong is really possible the cultural fossil of the composite canoe employed by the prehistoric Bai Yue people in the southern coast of China. 


\subsubsection{The Archaeological Discoveries of the Suspected Outrigger Canoes in Southeast Coast of China}

The discoveries of and comparisons between Mangka, Mother-Son Boat of the indigenous ethnics in southern China, and the outrigger canoes of Pacific Austronesian, provide us valuable references for the further researching of a number of important Neolithic and historic canoes which had been discovered as suspected outrigger remains in the Zhejiang, Fujian and Guangdong provinces in southeast coast of China.

Kuahuqiao canoe (8200-7500 BP) in Xiaoshan (萧山) county of Zhejiang is one prominent example. The canoe was dug into a pine log with residual hull of $5.6 \mathrm{~m}$ long, $0.52 \mathrm{~m}$ wide. The stern and upper board of the hull are lost. The maximum depth of hull inboard is less than $0.15 \mathrm{~m}$. On both sides of the hull remnant scattered some of "stake timbers" and "pieces of wood", with at least six long recumbent logs parallel to the hull, ranging in length from 2.5 to $2.8 \mathrm{~m}$, and with some other short pieces of wood roughly perpendicular to the hull and long logs (Fig. 7.15). Obviously, the layout of hull remnant and its parallel "long logs" and crossed "short wood" present the horizontal structural characteristics of a double outrigger canoe, including the floating "long logs" paralleling to canoe and the connective "short wood" booms. A piece of bamboo mats of $60 \mathrm{~cm}$ long and $50 \mathrm{~cm}$ wide suited at $6 \mathrm{~m}$ northeast of the canoe was inferred to be the sail remain. Therefore, the site excavator Jiang Leping (蒋乐平) speculated the remains of this canoe as an "outrigger canoe" of ancient China (ZJPICRA et al. 2004: 50).

The canoe of the Western Han Dynasty unearthed on the riverside of Aojiang (鳌江) River at Pukou (浦口) town of Lianjiang (连江) in Fujian, was dug into a

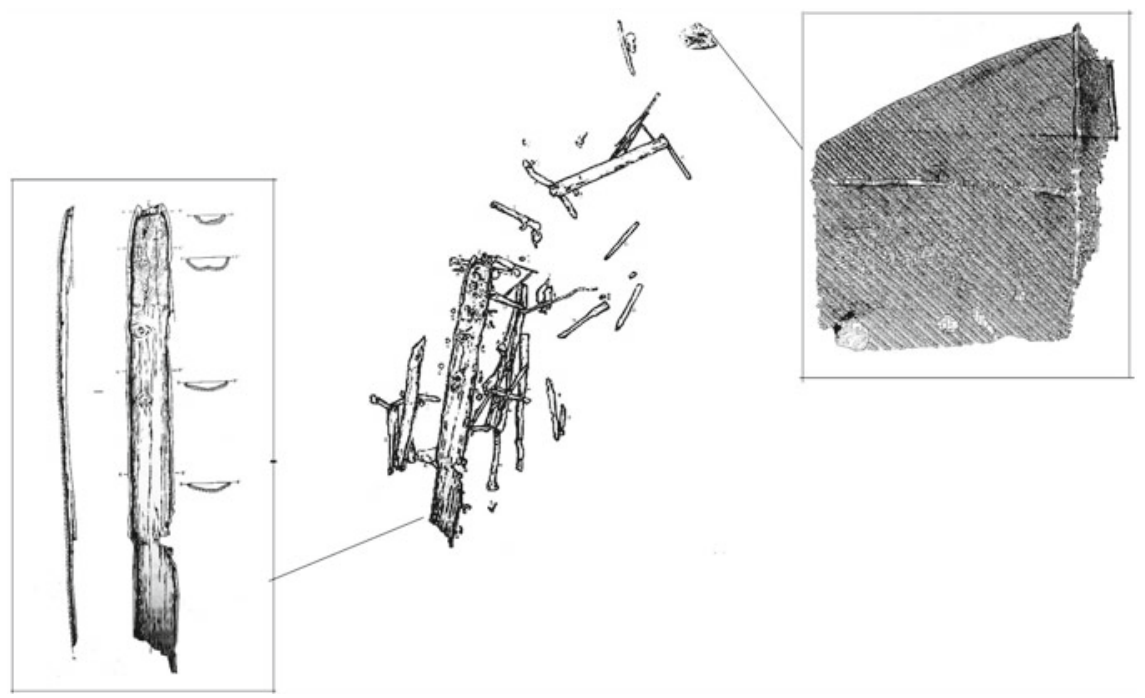

Fig. 7.15 The layout of a canoe remnant in Neolithic Kuahuqiao site of Zhejiang 
whole camphor log, with remnant of $7.1 \mathrm{~m}$ long, square-shaped board of its bow and stern, and flat and a little arced bottom in the cross section. Both sides of the hull washboard are much damaged. On both sides of the front washboard remain a pair of symmetrical grooves (Fig. 7.16). This structure is similar to the feature of upper inboard groove or perforated connectives for lashing booms of outrigger canoes in Pacific and Indonesia. At the bottom of the stern, more than a dozen log fragments about $6.5 \mathrm{~cm}$ in diameter have been excavated, coinciding with the float and booms of an outrigger (Lu, M.C. 1979).

Among the six canoes of Eastern Han Dynasty unearthed in the east bank of Jianjiang (鉴江) River at Shining (石宁) village in Huazhou (化州) County of Guangdong Province, the No. 2 canoe is basically undamaged, with remaining hull of $5 \mathrm{~m}$ long and $0.5 \mathrm{~m}$ wide at amidships. There are seven pairs of symmetrical bulged marks on each side of inboard with an interval of $0.23-0.6 \mathrm{~m}$. The right side of the inboard hull from the top to bottom has seven small round holes with a diameter of $1 \mathrm{~cm}$. These tenon and perforation are also consistent with the features for the related booms connectives of outrigger canoes shown in Pacific (ZJDM et al. 1979).

Besides, three canoe remains respectively with lengths of 9.2, 7.8 and $9.2 \mathrm{~m}$ were discovered from the Maolingjiang (茅岭江) River in Qinzhou (钦州), Guangxi, together with the collection of bronze shouldered axes dating to Zhou and Han dynasties. All three canoes have well-preserved 1-2 square or circular holes, or grooves on bow board or sterns board, being consistent with the booms connectives structures of an outrigger canoe. Another extended canoe joined by two sections of dugout hull was also collected in the lower reaches of Nanliujiang (南流江) River in Hepu (合浦) County of Guangxi, with a residual length of $6.2 \mathrm{~m}$ and a width of $1.05 \mathrm{~m}$. The perforation and groove structures on the two sides of washboard also fit well with the boom connectives of outrigger.

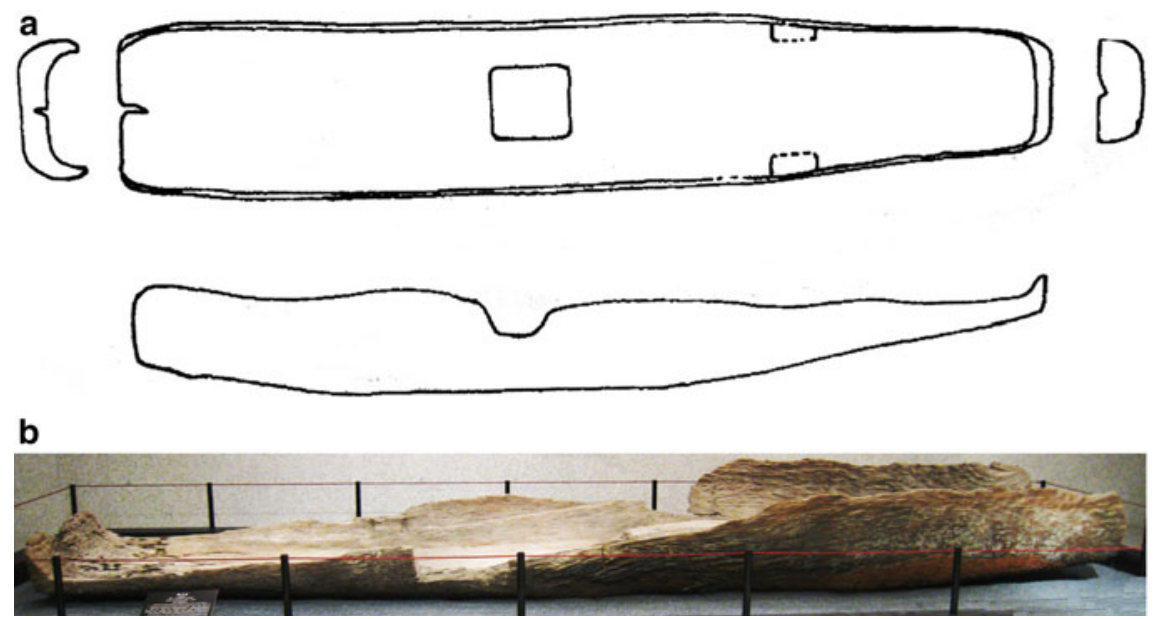

Fig. 7.16 The canoe of the Han Dynasty from Aojiang River of Lianjiang in Fujian 
Obviously, there are a number of canoes remains discovered in the southeast coast of China, with distinctively structural features related to the connectives of the float and booms of outrigger canoe in the prehistoric and early historical periods. They are very likely a kind of composite boat similar to the outrigger canoes of southeast Asia and Pacific. In particular, the remain of Neolithic Kuohuqiao canoe might be the oldest double outrigger, with the main body of hull, suspected apparatus of log floats, and connective booms. These suspected outrigger canoe remains, together with the ethnographical heritages of Mangka and Mother-Son Boat of southern China, provide evidences for the restoration of prehistoric seafaring craft of Bai Yue and Proto-Austronesian in southeast of China.

\subsection{An Investigation of the Boat Sail in Early Seafaring of Southeastern China}

The variant sails have generally been employed as main seagoing driving power in almost all prehistoric and early navigation in the world. Because most archaeological sites do not preserve the relics of prehistoric and early sails of the boat, scholars generally discussed the origin of Chinese sailing boats according to a few simple and vague records in ancient literature and then inferred that early boat sails might have been used in Three Dynasties, Qin or Han dynasties (CGHSBSHJTU, 1977; Lin, H.D. 1986; Wen, S.G. 1983; Yang, C. 1989). For instance, Luo Qi(罗 顾) said in the Material Origin (Wuyuan 物原) of Ming Dynasty: “Suiren (燧人) clan took dry gourd as float, Fuxi (伏羲) clan started to use raft, Emperor Xuanyuan (轩辕) made canoe, Emperor Zhuanxu (颛顼) made pole for boat, Emperor Yu (禹) of Xia Dynasty invented rudder, and further invented cabin, anchor, sail, and mast for the boat" (Luo, Q. 1985: 32). Liu Xi (刘熙) said in the section of "Explanation of Boats” (释船) of the Explanation of Names (Shi Ming 释名) of Han Dynasty that "A sail is a sheet of curtain released on boat in front of the wind, which pulling the boat going forward fast” (Liu, Xi. 1939: 129).

The sail is one of the most important seafaring apparatus of indigenous composite canoes in the Pacific, by which the Austronesian extended and disseminated to the far and open Indo-Pacific oceans. The characteristic sail of Pacific seafaring crafts is typically triangular sail made of coconut palm leaves, thin bamboo stripe mats, or plant fibers. These triangular sails mainly varied as two developing lines of spritsail and lateen sail respectively with evolving series. The spritsail included the simple or primitive spritsail with an inverted triangular sail bound to two long and straight spars used in New Zealand of Polynesia and Marquesas Islands, the crab-claw spritsail with the vertical mast spar and curled sprit throughout the length used in Hawaii, and the boom sprit sail used in Society islands (Haddon, A.C. et al. 1938: 45-47). As another evolving series, oceanic lateen sail varied as proto-lateen sail limited in the area of Indonesia, the primitive Oceanic lateen sail developed in Polynesia, and the true Oceanic originated and developed in Micronesia and Polynesia (Haddon, A.C. et al. 
1938: 48-52). In addition, in the New Britain of Melanesian islands, Siassi, the coast of New Guinea, the Torres Strait, and some other places, there was a small distribution of the original square sail (Haddon, A.C. et al. 1938: 52-54). Seafaring sails of Austronesian may have originated from the primitive double canoes and outrigger canoes used by proto-Austronesian or indigenous Bai Yue since the Neolithic age. The varieties of triangular sail of Pacific provide specific reference for investigating prehistoric seaworthy sail in southeast China.

In the Kuahuqiao site where the suspected outrigger canoe was unearthed, a few pieces of mat remains woven with bamboo strips were found together with the canoe. At $6 \mathrm{~m}$ northeast of the canoe hull is a piece of mat (artifact No. 30) of $60 \mathrm{~cm}$ long and $50 \mathrm{~cm}$ wide. Though the purpose of this woven bamboo mat has so far not been identified, its coexistence with the canoe hull and the speculated floats and booms of an outrigger, and its shape of the plan, directed to remains of the primitive sail of a boat. And, besides the layout of the outrigger apparatus, a cluster of stake woods obliquely lying to the northeast of the canoe hull and next to No. 30 bamboo mat could also be mast spar for the boat sail, which is similar to mast spar for spritsail or mast pole for lateen sail in the Pacific. Interestingly, the residual mat is trapezoidal plan with three damaged sides, and a T-shaped wooden frame crossing interior of the woven and slantingly connecting the intact side, showing the possibility of its triangular plan. This is exactly consistent with the triangular feature of both the sprit sail and lateen sail of the Pacific. The bamboo strip woven sail mat was also discovered in the shipwreck site of Song Dynasty in Quanzhou of Fujian, showing the long tradition of bamboo sail making on junk of southeast of China (QZMMFJ 1987: 45-46; Fig. 5.2). The section of "Boat" of A New Introduction to Guangdong of the Qing Dynasty also records that the boat sails of Guangzhou were mostly woven straw mat (Qu, D.J. 1985: 476). Therefore, it is quite possible that the Kuahuqiao canoe is a double outrigger with triangular sail suitable for prehistoric seafaring, which is consistent with the role of the Kuahuqiao Culture as both one of the early Neolithic cultures in southeast China and potential origins of maritime culture in the Asia-Pacific regions.

The sailing raft and catamaran investigated and recorded in the ethnographies of southern China and Southeast Asia provides more proof for the seafaring sail of the primitive canoe. The rafts made of floating logs, reeds, and bamboo poles lashed together in parallel, were still in use by the boatman until recently in south of China, such as the fishing rafts, bamboo rafts, and the floating cargo platforms commonly witnessed along the coast and rivers in Fujian and Guangxi. The sailing rafts and catamaran were also found from Taiwan to the Polynesian islands. For example, in 1826, large sailing rafts and catamarans were investigated on Mangarevan island, on which the paddles and spritsail were combined (Haddon, A.C. et al. 1938: 14). In 1954, Professor Ling Chunsheng recorded a large bamboo raft on Kaohsiung beach of Taiwan, which was bound with 11 bamboo poles and used a large trapezoidal sail in amidships of the board (Ling, C.S. 1970: 78). Researchers believed that such kind of sailing rafts had also been the seafaring craft carrying the Proto-Austronesian from the mainland southeast of China to Southeast Asian archipelago (Rolett, B.V. 2007). 


\subsection{Conclusion}

The Pacific double canoes and outrigger canoes had been the prominent seaworthy crafts with stabilizing structure for thousands of years, which had been connected technically in composite layout with significant lateral damp. According to analysis and summary of A. C. Haddon and J. Hornell's, a double canoe may be made by connecting two dugouts or increasing in size of the float of a single outrigger canoe, a double outrigger may be made by developing a boomed out balance on two sides of a dugout or duplicating another outrigger for a single outrigger, a single outrigger may be made by eliminating one outrigger of a double outrigger canoe or diminishing one hull of a double canoe, and a two or three logged raft may develop into a double canoe, single outrigger canoe or double outrigger canoe (Haddon, A.C. et al. 1938: 44-45).

The common features of these composite Austronesian canoes in the Indo-Pacific region, with double canoe and outrigger canoe as the main feature, are very distinctive. They not only overcome the weakness of a single canoe of being easy transverse swing and even capsizing by unique lateral damp of its composite layout, but also keep the advantage of lightness and flexibility of canoe and even acting as positive buoyancy in seafaring. These composite canoes with Oceanic spritsail or lateen sail were stably seaworthy crafts of Austronesian seagoing in the Pacific. For the close cultural relationship of the prehistoric indigenous Bai Yue and the Proto-Austronesian, the double-hulled boat Fang or Fangzhou, the double outrigger Mangka and Mother-Son Boat in ethnographical records and a number of suspected outrigger canoes in the archaeological remains along coast of Eastern Asia were consistent with the content of the composite canoes in Indo-Pacific oceans. They might be historical fossils of the similar composite canoes of prehistoric seafaring of indigenous Bai Yue, or the logical prototype of Austronesian double canoe and outrigger canoe, which is of great significance in the cultural history of the Asia-Pacific region.

Open Access This chapter is licensed under the terms of the Creative Commons Attribution 4.0 International License (http://creativecommons.org/licenses/by/4.0/), which permits use, sharing, adaptation, distribution, and reproduction in any medium or format, as long as you give appropriate credit to the original author(s) and the source, provide a link to the Creative Commons license, and indicate if changes were made.

The images or other third party material in this chapter are included in the chapter's Creative Commons license unless indicated otherwise in a credit line to the material. If material is not included in the chapter's Creative Commons license and your intended use is not permitted by statutory regulation or exceeds the permitted use, you will need to obtain permission directly from the copyright holder.

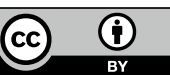

